\title{
Ansätze zur quantitativen Analyse der Nachrichtenaufnahme und -verarbeitung in biologischen Rezeptoren
}

\author{
Ekkehard Zerbst, Karl-Heinz Dittberner \\ und ERICH WILLiam
}

Physiologisches Institut der Freien Universität Berlin, Berlin

\begin{abstract}
Approaches to quantitative analysis of information uptake and processing in biological receptors. The flux equilibrium theory, used for interpretating active and passive ion transport, can explain the generation of receptor potentials. In a model, driving forces and velocity coefficients are represented by the parameters of electric circuits. From these membrane models ionic fluxes can be calculated quantitatively on the basis of transport equations. These equations are derived from the theory of irreversible thermodynamic processes. Receptor models allow a simulation and prediction of the bioelectric potentials which were recorded by other authors in neuro-physiological experiments under various stimulus conditions. The information capacity of a single receptor channel is determined by the ionic flux and the stimulus parameters. In combination with the network of neuron models, receptor models can be used in a perceptron. The problems of on-off-activation and lateral inhibition were investigated with such a network.
\end{abstract}

\section{EINLEITUNG}

Durch die Untersuchungen der Arbeitsgruppe von ADRIAN (1928) ist bekannt, daß Informationen über die auf einen Rezeptor einwirkende Reizintensität durch Impulsraten-Codierung des sensiblen Nerven übertragen werden. Die membranphysiologischen Grundlagen der Einzelimpulsbildung sind relativ weitgehend aufgeklärt (HodGKin \& Huxıex 1952); sehr gering sind bisher jedoch die Kenntnisse über den Primärprozeß der Informationsaufnahme durch rezeptorische Endorgane. Der Rezeptor steuert über sein Generator- beziehungsweise Rezeptorpotential (evtl. elektrotonisch) die Rate der fortgeleiteten Potentiale des sensiblen Nerven. Anstiegssteilheit, Amplitude und Form des Generatorpotentials sind eine Funktion der Reizform und -intensität. Die Vorgänge der Rezeptorpotentialbildung sind für einige Teilgebiete der quantitativen Biologie von besonderem Interesse. Das betrifft vor allem die Membranund Erregungsphysiologie, die biologische Informationstheorie und Biokybernetik.

Ziel der vorliegenden Untersuchungen ist die theoretische Analyse derjenigen Vorgänge, welche die Entstehung und den Zeitgang der graduierten Rezeptorpotentiale 
bedingen können. Im Organismus findet man drei Prinzipien biologischer Meßfühler: (a) Meßfühler mit Proportional-Empfindlichkeit, sogenannte P-Rezeptoren, (b) Meßfühler mit Differentialquotienten-Empfindlichkeit, sogenannte D-Rezeptoren und (c) Meßfühler mit Proportional- und Differentialquotienten-Empfindlichkeit, das heißt PD-Rezeptoren. Die letzte Gruppe ist am häufigsten anzutreffen. Ihr Prinzip gilt unter anderem für die Presso-, Photo- und Thermorezeptoren. Die nachfolgenden Betrachtungen beziehen sich hauptsächlich auf diese Gruppe der PD-Rezeptoren.

\section{METHODIK}

Im allgemeinen durchläuft die Physiologie vier typische Stadien der Problembetrachtung: Im ersten Stadium wird das Objekt beobachtet. Aus den Beobachtungsergebnissen werden erste empirische Regeln abgeleitet. So lassen sich aus der Reaktion

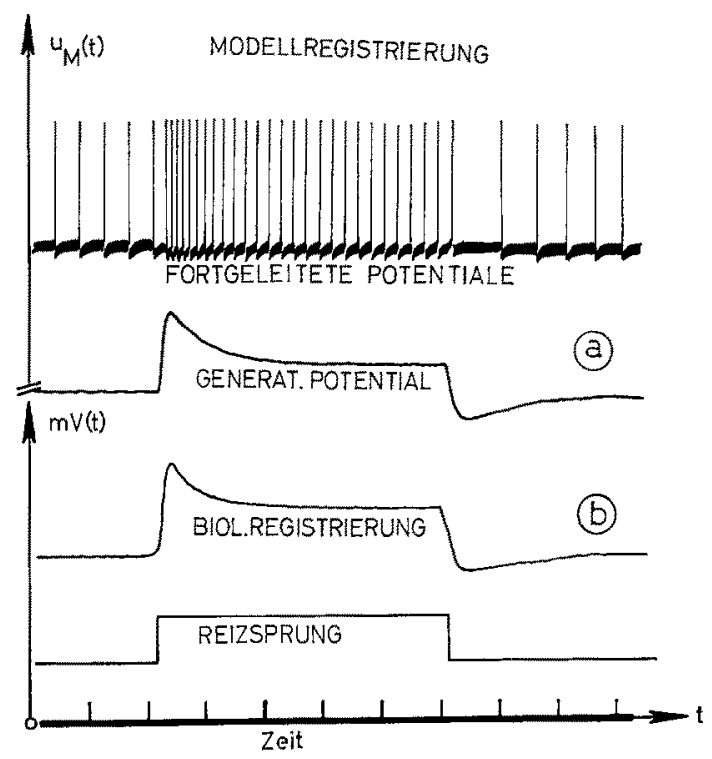

Abb. 1: Fortgeleitete Potentiale (oben) und Generatorpotentiale ( $a$ und b) eines PD-Rezeptors. Nad Beginn des Reizsprunges steigt das Generatorpotential iberschießend an und fält danach bei gleichbleibender Reizstärke näherungsweise exponentiell auf den reizstärkenproportionalen steady-state-Wert ab. Die Impulsrate der fortgeleiteten Potentiale ist der jeweiligen Höhe des Generatorpotentials proportional. Die Registrierung der 1. und 2. Reihe wurden mit dem in Abbildung 15 dargestellten Rezeptormodell aufgenommen. Bei den Registrierungen der 3. Reihe handelt es sich um die Nachzeichnung eines Originalversuches von BURKFARDT (1962)

eines Rezeptorgliedes auf einen zeitlich rechteckig verlaufenden Einheitsreiz beispielsweise empirische Regeln über die Form des Rezeptorpotentials ableiten (Abb. 1).

Im zweiten Stadium werden die empirischen Regeln experimentell verifiziert, indem zum Beispiel die Rezeptorreaktionen unter verschiedenen Bedingungen untersucht und quantitative Gesetze aufgestellt werden. Die Funktion eines Rezeptors erschöpt 
sich nicht darin, das bloße Vorhanden- oder Nichtvorhandensein einer bestimmten Reizqualität anzuzeigen. Rezeptoren sind vielmehr so eingerichtet, daß der Reiz beziehungsweise der Reizvorgang quantitativ analysiert wird. Ein PD-Rezeptor informiert über Anstiegssteilheit der Reizwirkung, absolute Größe der Reizintensität und die Größe des Grundreizes.

Im dritten Stadium werden die Regeln und Gesetze mit den strukturellen, energetischen und biochemischen Grundeigenschaften des Objektes koordiniert. Aus dieser Koordination ergeben sich Vermutungen beziehungsweise Arbeitshypothesen zur Ursache des untersuchten Vorganges.

Im vierten Stadium wird schließlich durch gezielte experimentelle Ansätze die Arbeitshypothese überprüf. Werden alle Folgerungen aus der Hypothese bestätigt, dann verdichtet sie sich zur Theorie.

$\mathrm{Zu}$ den beiden ersten Stadien der Problembetrachtung hat die experimentelle Neurophysiologie bereits umfangreiche qualitative und quantitative Befunde erbracht. Unter Verwendung dieser Befunde aus dem Bereich der experimentellen Physiologie beginnen die nachfolgenden Erörterungen praktisch mit dem dritten Stadium der Problembetrachtung: Das Ziel ist die Koordination der qualitativen Regeln und der quantitativen Gesetze der Rezeptorfunktion mit den ïbrigen thermodynamischen und energetischen Grundeigenschaften biologischer Systeme. Diese Koordination wird im Sinne der „integrativen Physiologie ${ }^{\alpha}$ in mehreren Schritten erreicht.

Dex erste Schritt führt zu der Frage: Welche regeltechnischen, physikalischen oder thermodynamischen Systeme zeigen ähnliche Einschwingvorgänge wie das Rezeptorpotential biologischer PD-Meßglieder? Die Eigenschaften eines „Eingangsgliedes“ kommen zum Ausdruck, wenn man seine Reaktion auf einen Einheitsreiz untersucht (vgl. Abb. 1). In Form und Verlauf dem Rezeptorpotential „ähnliche“ Einschwingvorgänge findet man nach einem "Einheitsreiz" bei drei verschiedenen Systemen: 1. Bei Regelungsvorgängen mit Rückkopplung (vgl. Drischet 1952); 2. bei physikalischen Systemen, die den Gesetzen der Beschleunigung und Massenträgheit folgen, zum Beispiel beim Galvanometer (vgl. KEIDEL 1955/56); 3. bei thermodynamisch offenen Systemen mit Staustufen und kapazitiven Kompartimenten, das heißt bei Fließgleichgewichtssystemen (vgl. Burton 1939, v. Bertalanffy 1951, 1953, 1962, 1964, MeiXner \& REIK 1959).

Obwohl im Sinneszellstoffwechsel für die Bildung des Generatorpotentials Regelungsvorgänge mit Rückkopplung (Regulationen zweiter Ordnung) theoretisch in Frage kommen können, sollen sich die nachfolgenden Untersuchungen auf die Untersuchung einfacher Fließgleichgewichtssysteme beschränken. In diesen Systemen laufen nur Regulationen erster Ordnung (v. BERTALANFFY 1964) ab, das heißt „Regulationen“" die nicht an Rückkopplungspfade gebunden sind.

Biologische Systeme sind thermodynamisch offen, es finden permanent energetisch irreversible Prozesse statt. Pauschal lassen sich diese Systeme durch einfache Fließgleichgewichtsmodelle abbilden (Burton 1939, v. BerTALANFFY 1951, 1953, 1962, 1964, Denbigh \& Hrcks 1948, Behmann \& Meissner 1961, 1962, Zerbst 1963a, b, c, d), und zwar durch (a) chemische Fließgleichgewichtsmodelle, (b) hydrodynamische Fließgleichgewichtsmodelle und (c) elektrische Ersatzschaltungen für Fließgleichgewichtssysteme (Abb. 2). 
Abbildung 2 zeigt Modelle dieser Art, sie sind alle durch formal identische Differentialgleichungen $\mathrm{zu}$ charakterisieren. Selbstverständlich können auch definierte und weitaus komplexere biochemische oder bioelektrische Vorgänge durch analoge Modellsysteme mit entsprechend charakteristischen Parametern abgebildet und im Sinne der Analogrechnung behandelt werden.

Es soll aber vorerst die allgemeine Frage untersucht werden: Wie weit zeigen PDRezeptoren und einfache Fließgleichgewichtssysteme phänomenologisch gleiche Reak-

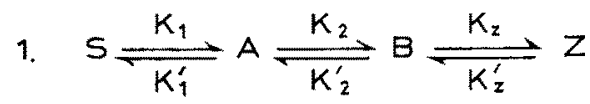

ANALOGVORGÄNGE
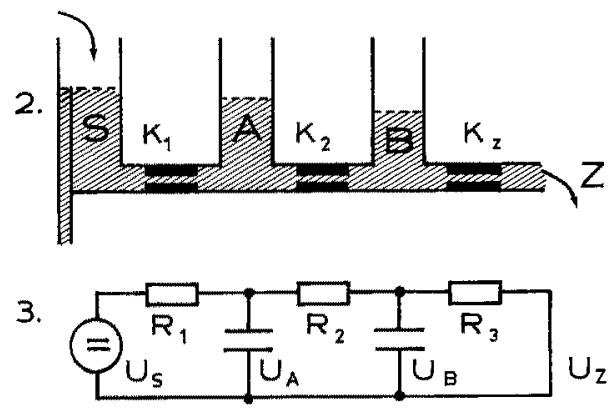

Abb. 2: Chemisches (1), hydrodynamisches (2) und elektrisches (3) Modell eines Fließgleichgewichtssystems. Bei (1) verläuft die Realktion im offenen System nettomäßig irreversibel von links nach rechts $\left(k_{2}\right.$ ist um Zehnerpotenzen größer als $\left.k_{2}^{\prime}\right)$. Bei Anderung der Koeffizientengröße von $k_{2}$ kommt es zu Fließgleichgewichtsveränderungen der Substanzkonzentrationen $A$ und $B$, wenn $S$ fortlaufend ergänzt und $Z$ aus dem System entfernt wird. Entsprechend verändern sich die hydrodynamischen Drucke A und B im Modellsystem (2), wenn der Leitwert $k_{2}$ verändert wird. Wird letzterer zeitlich rechteckig vergrößert, steigt der Druck B initial iberschießend an, fällt dann jedoch - wegen des Absinkens des Druckes A - allmählich auf einen neuen steady-state-Wert $\mathrm{ab}$. Bei Verringerung des Leitwertes $k_{2}$ nimmt der Druck $\mathrm{B}$ zuerst unterschießend $a b$, weil die treibende Kraft des Druckes $A$ bei verringertem Leitwert zuerst nur einen relativ geringen Fluß von $A$ nach $B$ bedingt; anschließend steigt der Druck $A$ jedoch wegen der vergrößerten Stauwirkung des Leitwertes $k_{2}$ langsam an und erhöht damit auch gleichzeitig die Stromstärke (Umsatzrate) von A nach B. Infolgedessen steigt der Druck B wieder auf seinen Ausgangswert. Ein entsprechendes Verhalten zeigt im elektrischen Modell die Spannung $U_{B}$

tionen auf reizbedingte Parameterveränderungen? Diese Frage kamn für einfache Fließgleichgewichtssysteme rechnerisch gelöst werden (Burton 1939). Die Methode ist aber sehr aufwendig. Deshalb werden nachfolgend Modellversuche im Sinne der Analogrechnung durchgeführt (Abb. 2). Voraussetzung für eine sinnvolle Durchführung solcher Modellversuche ist die Größenanalogie der Parameter (ZERBST \& WILliam 1964). Es wird von folgenden Grundannahmen ausgegangen:

(a) Am biologischen Objekt (Rezeptormembran) wird durch einen Reiz eine Koeffizientenveränderung ausgelöst ( $z$. B. Veränderung von Enzymaktivitäten, Membranpermeabilitäten etc.) (vgl. Hodgkin \& HuxLEy 1952). Die Reiz-Energie geht nicht in den energetischen Fluß oder die energetische Bilanz des ausgelösten Reaktionsvorganges ein. 
(b) Bei der Untersuchung der Reiz-Reaktionsbeziehungen am Fließgleichgewichtsmodell werden in Analogie zu den für den biologischen Vorgang getroffenen Grundannahmen ein oder mehrere Koeffizienten des Systems verändert. (Am chemischen Modell wären das Reaktions- oder Diffusionsgeschwindigkeitskoeffizienten, am hydrodynamischen Modell reziproke Widerstände, am elektrischen Modell Leitwerte.) Relativ einfache methodische Bedingungen erhält man bei der Anwendung des elektrischen
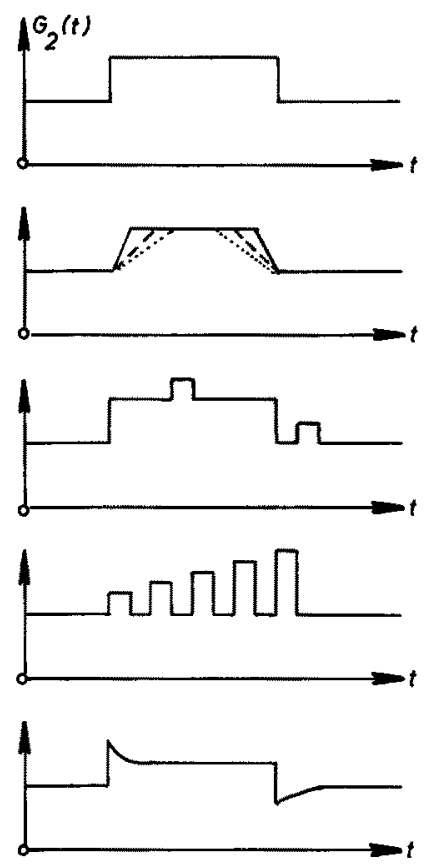

Abb. 3: Übersicht zur reizstärkenproportionalen Veränderung des Leitwertes $\mathrm{G}_{2}$ bei den Modellversuchen zur Reiz-Reaktionsbeziehung am elektrischen Fließgleichgewichtssystem der Abbildung 2 (3). $\mathrm{G}_{2}$ als Funktion der Zeit. Von oben nach unten: 1. Reihe: Reizsprung. 2. Reihe: Reizstärkenveränderungen unterschiedlicher Anstiegssteilheit. 3. Reihe: Konditionsreiz mit aufgesetzten Testreizen. 4. Reihe: Stufenweise Reizstärkenvergrößerung. 5. Reihe: Über- beziehungsweise unterschießender Zeitgang der Reizstärke

Fließgleichgewichtsmodelles (realisiert durch elektrische Schaltelemente oder programmiert auf einem kommerziellen Analogrechner). Die nachfolgenden Versuche wurden mit diesem Modellprinzip durchgeführt. Am elektrischen Vierpol wird in Analogie zur parametrischen Beeinflussung des lebenden Systems durch den Reiz der Leitwert $\mathrm{G}_{2}$ verändert. Bei steigender Reizintensität wird er vergrößert, bei fallender Intensität verringert (Abb. 3). Als Kriterium für den „Reizerfolg“, d. h. für die Reaktion des Systems wird das Potential $\mathrm{U}_{\mathrm{M}}$ an der Kapazität $\mathrm{C}_{2}$ registriert. Diese Spannung ist eine Intensitätsgröße und damit den biochemischen Intensitäten (Substanzkonzentrationen beziehungsweise Partialdruck einer Substanz) oder den bioelektrischen Intensitätsgrößen (Rezeptor- beziehungsweise Generatorpotential) größenanalog. 


\section{REIZARTEN UND REZEPTORPOTENTIALANDERUNGEN AM MODELL}

Sprungreiz: Auf einen Sprungreiz antwortet das Fließgleichgewichtssystem mit initial überschießender Reaktion (Abb. 4a). Anschließend stellt es sich näherungsweise exponentiell auf einen endgültigen steady-state-Wert ein. Erfolgt der Reizsprung von der Basis der Reizstärke Null, ist also kein Grundreiz (bei Photorezeptoren zum Beispiel die Hintergrundbeleuchtung) vorhanden, dann stellt sich das Rezeptorpotential bei Reizabwärtssprung exponentiell auf seinen ursprünglichen Wert ein. Wird dagegen der Reizsprung einer gewissen Grundreizstärke aufgesetzt, dann folgt auf Absetzen des Reizes eine unterschießende Reaktion (Abb. 4b). Das Modell zeigt gleiche Reaktionen wie das biologische Objekt (vgl. Krkuchi 1960, BurkHardt 1962).

Einschleichende Reizstärkenvergrößerung: Je nach Steilheit der Reizeinwirkung zeigt die Reaktion (Rezeptorpotential) ein unterschiedliches

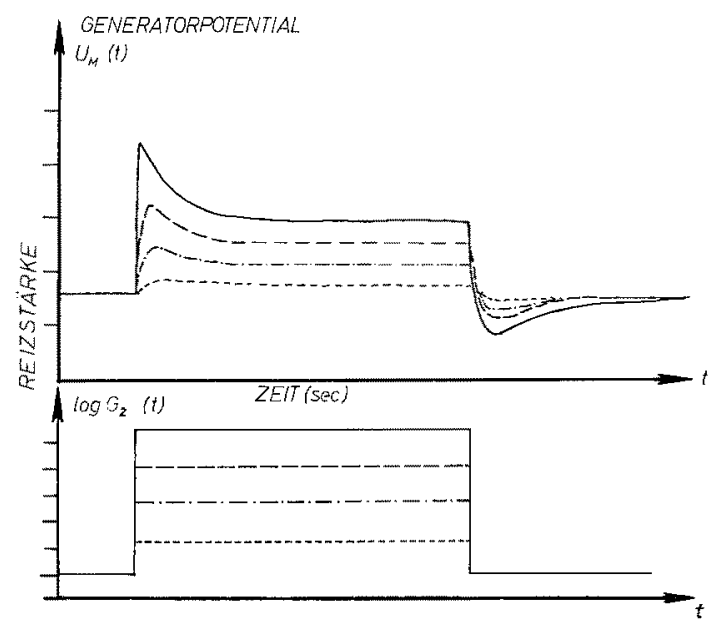

Abb. 4a: Generatorpotential UM als Funktion der Zeit und der Reizintensität G2. Die Reizstärkenskala beginnt bei einem Wert größer als Null; vor dem Reiz-Rechtecksprung ist also bereits eine gewisse Grundreizstärke kontinuierlich wirksam. Mit zunehmender Amplitude der Reizstärke erhöht sich der überschießende Anteil des Generatorpotentials, desgleichen der unterschießende. Die Zeitkonstante des Einstellvorganges auf den endgültigen steady-state-Wert wird mit zunehmender Reizstärke kleiner. (Nachzeichnungen von Modell registrierungen aus Zerbst, Dittberner \& William 1965b)

Verhalten. Bei steilem Reizanstieg ist die überschießende Komponente stark ausgeprägt. Bei geringer Steilheit ist schließlich keine überschießende Komponente der Reaktion mehr vorhanden (Abb. 5). Das Modell zeigt mit dem biologischen Objekt übereinstimmende Reaktionen (ADRIAN 1928, THURM 1964).

Konditions- und Testreiz: Werden einem Konditionsreiz geringer Amplitude Testreize höherer Amplitude aufgesetzt, dann zeigt das System die in Abbildung 6 dargestellten Reaktionen. Fallen Testreize in die überschießende Phase des Konditionsreizes, dann antwortet das System mit relativ hohen Reaktionsamplituden. 
Diese nehmen $a b$, wenn die Testreize in die Phase des steady-state der KonditionsreizReaktion fallen. Nach Absetzen des Konditionsreizes nehmen die Reaktionsreizamplituden allmählich wieder zu. Das Modell zeigt gleiche Reaktionen wie das biologische Objekt (Mechanorezeptoren) (Thurm 1964).

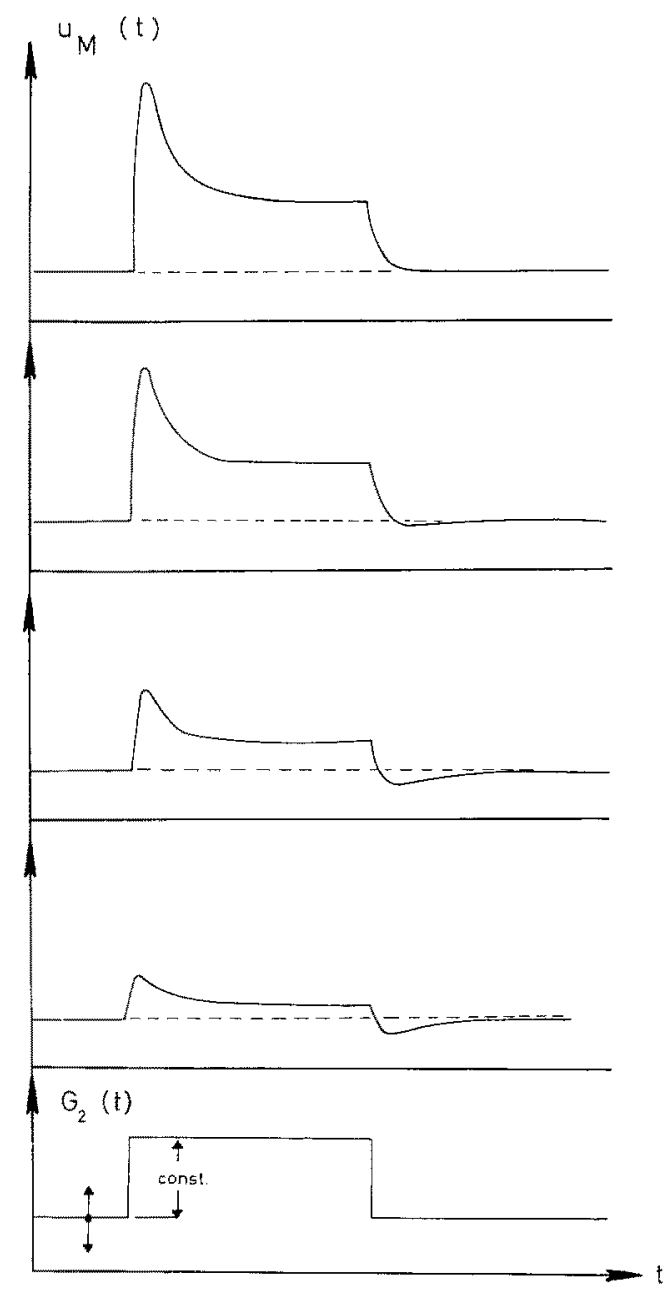

Abb. 4b: Abhängigkeit des Generatorpotentials von der Grundreizstärke vor Testreizung. (Nachzeichnung von Originalregistrierungen mit dem Rezeptormodell der Abb. 15.) Von oben nach unten: 1. Reihe: Grundreizstärke gleich Null. Das System zeigt beim Absetzen des Reizsprunges keine unterschießende Reaktion. 2. bis 4. Reihe: Mit zunehmender Grundreizstärke nimmt bei stets gleicher Testreizamplitude das Generatorpotential ab. Gleichzeitig wird die unterschießende Komponente verstärkt. Sie vermittelt Informationen über die Steilheit des Reizabwärtssprunges

Stufenweise Reizstärkenerhöhung: Wenn die Einheitsreize in ihrer Intensität stufenweise erhöht werden, dann nimmt die überschießende Komponente der Reizreaktion zu und die Zeitkonstante der steady-state-Einstellung ab. Trägt 
man die Spitzen- oder steady-state-Werte der Reaktionsamplituden gegen den logarithmischen Wert der Reizintensität (hier Leitwert $\mathrm{G}_{2}$ ) auf, dann erhält man statische und dynamische Kennlinien, die die Unterschiedsschwellenempfindlichkeit des Systems in den verschiedenen Bereichen der Reizstärkenskala charakterisieren (Abb. 7). Je nach
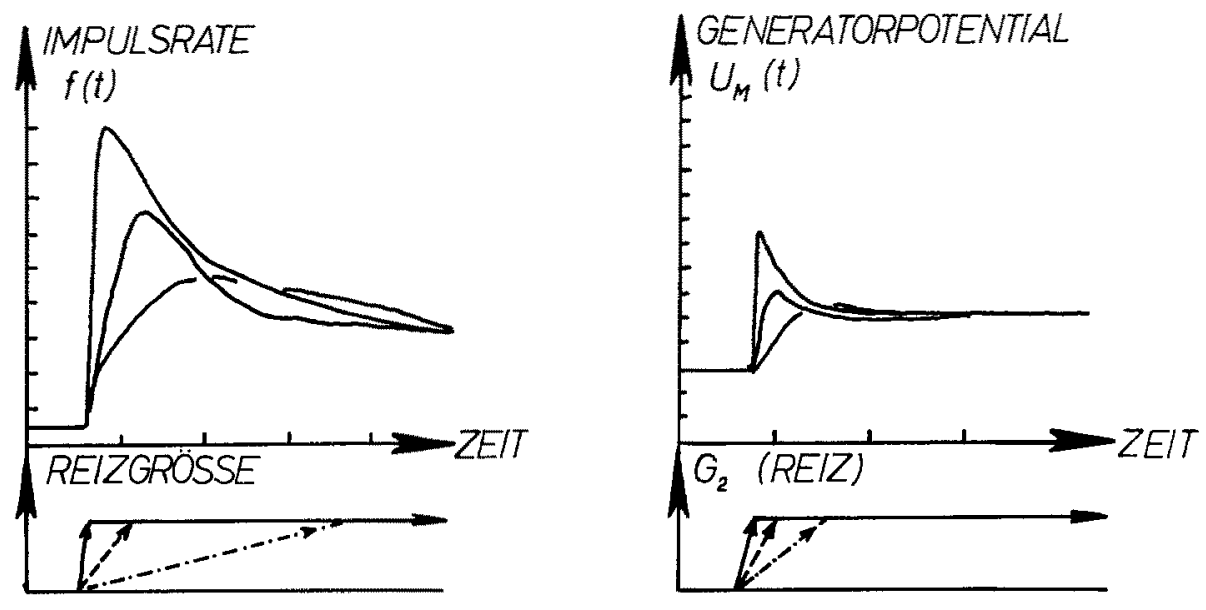

Abb. 5: Reiz-Reaktionsbeziehungen bei unterschiedlich steil einsetzenden Reizen gleicher Amplitude. Links: Nachzeichnung einer Originalregistrierung von ADRIAN (1928). Rechts: Nachzeichnung einer Modellregistrierung mit dem Rezeptormodell der Abbildung 15. Das Flächenintegral der überschießenden Komponente (Negativ-Entropie-Produktion des Systems, ZERBST 1964) vermittelt bei definierten Reizamplituden Informationen über die Reizsteilheit

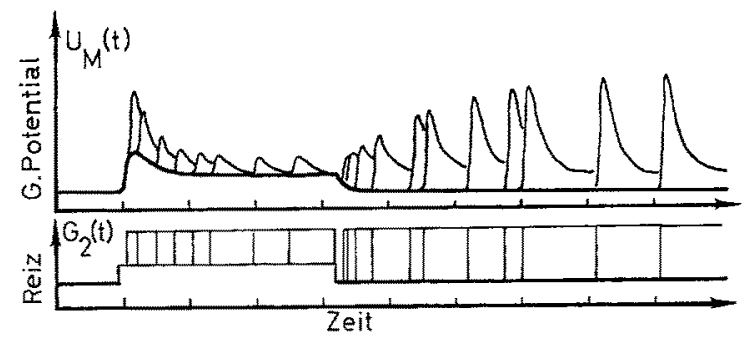

Abb. 6: Bezichungen zwischen Konditionsreiz und aufgesetzten Testreizen (übereinandergezeichnete Originalregistrierungen mehrexer Modellversuche). Auf einen Konditionsreiz (dick ausgezogene Linie unten) werden zu verschiedenen Zeitpunkten Testreize (dünn ausgezogene Linien) gleicher Amplitude aufgesetzt. Treffen die Testreize in die überschießende Komponente der Konditionsreizreaktion, dann wird die Amplitude der Testreizreaktion relativ gros. Sie fällt auf einen geringeren Wert $a b$, sobald sich die Konditionsreizreaktion auf den steady-stateWert eingestellt hat

Größe des Leitwertes $G_{1}$ (Adaptationszustand) varïert außerdem die Steilheit der Kennlinien. Das Modell zeigt gleiche Charakteristiken wie das biologische Objekt (vgl. BURKHARDT 1962).

Reiz mit initial überschießender Intensität: Erfolgt der Sprungreiz nicht zeitlich rechteckig, sondern beispielsweise mit initial überschießender 
Stärke, dann erhöht sich die überschießende Reaktion des Systems erheblich (Abb. 8). Nimmt man an, daß der Erregungssubstanz-Stoff wechsel durch den Reiz parametrisch beeinflußt wird und die Erregungssubstanz (Transmitter) bei Rechteckreiz einen überschießenden Konzentrationsanstieg aufweist, dann wird unter der parame-

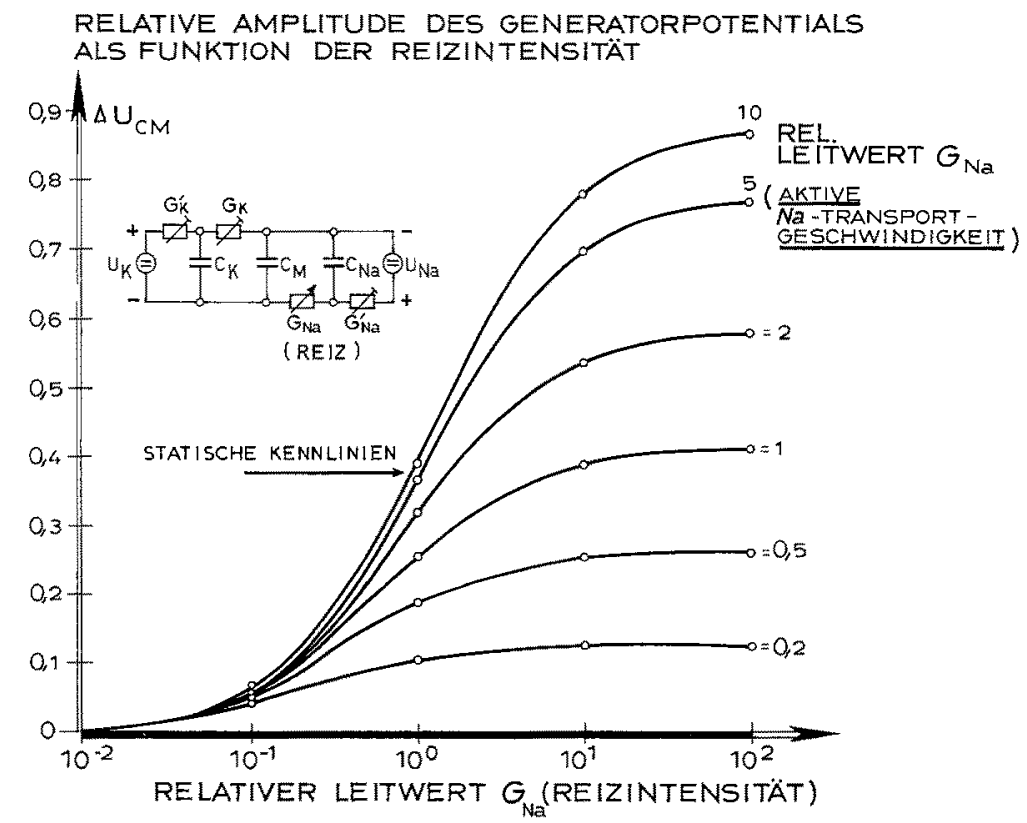

Abb. 7: Statische Kennlinien für die Rezeptorpotentiale eines erweiterten Rezeptormodelles. (Nach Zerbst, DiTTBerner \& William 1965)

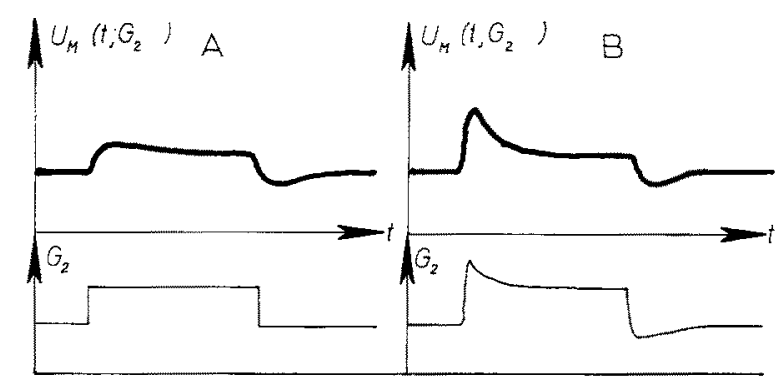

Abb. 8: Beziehungen zwischen der Form von Reizsprung und Rezeptorpotential (Nachzeichnungen der Registrierungen mit Rezeptormodellen). Links: Reaktion auf Rechteck-Reiz. Rechts: Reaktion auf einen Reiz initial überschießender Intensität

trischen Einwirkung dieser Transmitterkonzentration auf die Fließgleichgewichtssysteme des Elektrolyttransports an der Rezeptormembran (ZERBST, DitTberner \& WILLIAM 1965) die überschießende Komponente des Ionenpotentials (Rezeptorpotentials) noch verstärkt. Bei höheren Reizintensitäten kann der Abfall der Erregungssubstanzkonzentration nach der überschießenden Phase so steil sein, daß an der Mem- 
bran eine unterschwingende Phase auf die überschießende Potentialkomponente folgt, bevor sich ein endgültiger steady-state einstellt. (Solche unterschwingenden Phasen sind auch bei höheren Reizeinwirkungen auf biologische Rezeptoren zu registrieren.)

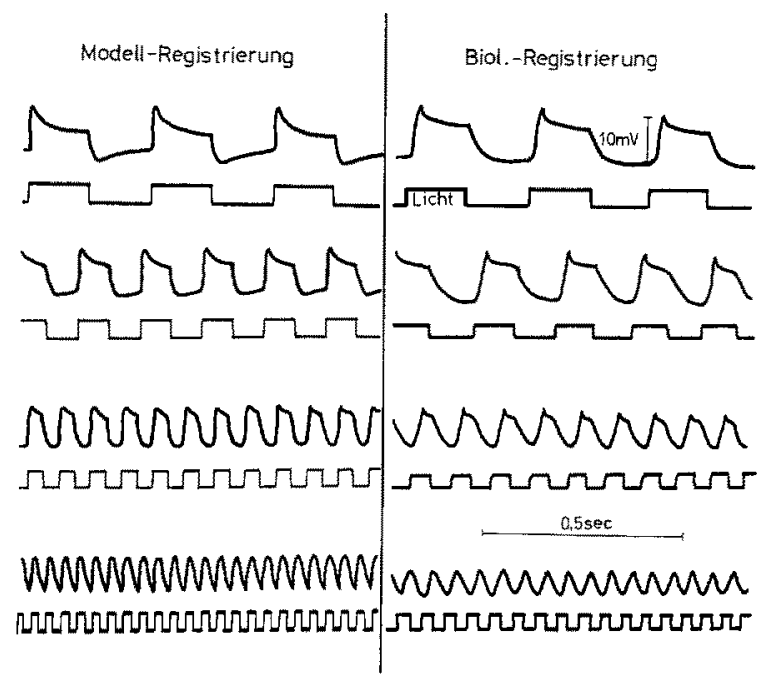

Abb. 9: Beziehungen zwischen Reizfrequenz und Reaktionsamplitude. Links: Modellregistrierungen. Rechts: Nachzeichnung entsprechender Originalregistrierungen von GrüssER (1952). In den jeweiligen Reihen oben: Rezeptorpotential, darunter: Reizsprung

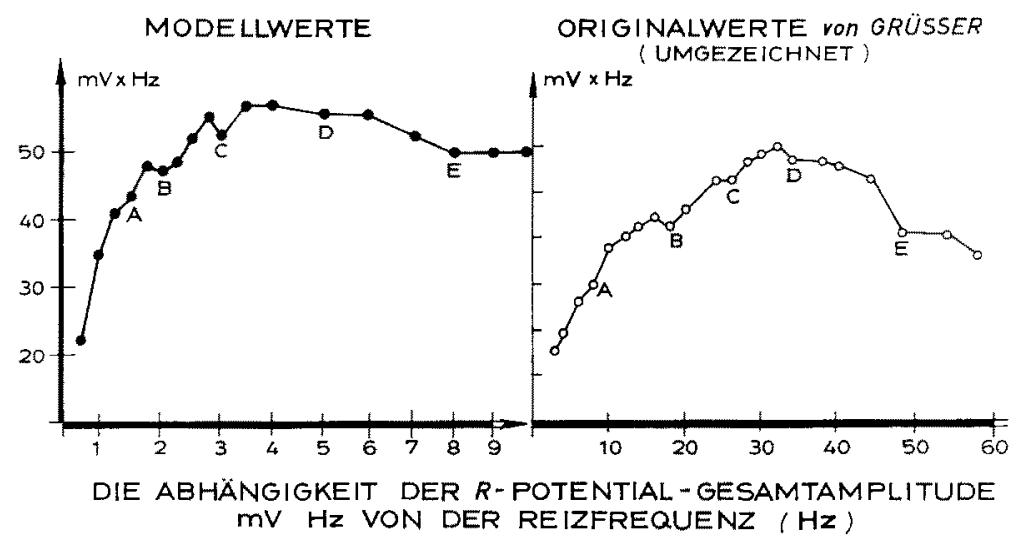

Abb. 10: Gesamtamplitude (Produkt aus Reaktionsamplitude und Reizfrequenz) als Funktion der Reizfrequenz. Links: Auftragung für die Modellwerte der Abbildung 9. Rechts: Auftragung für die Originalwerte von GRÜsSER aus Abbildung 9. Modell- und Originalwerte zeigen in den Abweichungen von der Kurvenstetigkeit in Richtung und Reihenfolge prinzipielle Übereinstimmungen

Amplituden-Frequenzabhängigkeit des Systems: Mit zunehmender Frequenz einer Rechteck-Reizfolge nehmen die Reaktionsamplituden ab. Außerdem verändert sich ihre Form in charakteristischer Weise (Abb. 9). Bildet man 
das Produkt aus Reaktionsamplitude und Reizfrequenz ("Gesamtamplitude“) und trägt es gegen die Reizfrequenz auf, dann ergibt sich eine Kurve mit unstetigem Verlauf, die die Resonanzeigenschaften des Systems kennzeichnen könnte (Abb. 10). Das Modell zeigt gleiche Eigenschaften wie das biologische Objekt (Grüsser 1951).

Modellverhalten spezieller Rezeptoren: Die Ergebnisse aller bisherigen Modellversuche decken sich mit den neurophysiologischen Befunden an biologischen PD-Rezeptoren (z. B. Kikuchi 1960, Adrian 1928, Thurm 1964, BurkHARDT 1962, GRÜsSER et al. 1951). Nun gibt es jedoch spezielle Rezeptoren, die in ihrem Verhalten von dem der übrigen PD-Meßfühler abweichen. Dazu gehören zum

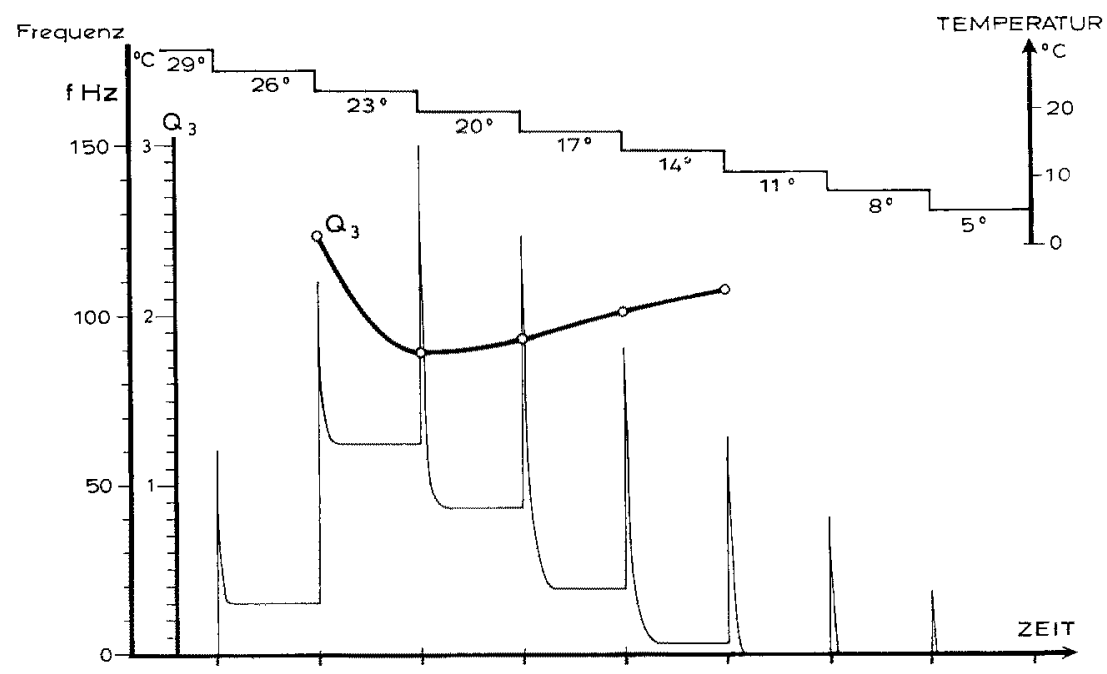

Abb. 11: Beziehungen zwischen Frequenz der fortgeleiteten Impulse eines temperaturempfindlichen Rezeptorsystems (Lorenzinische Ampullen), Temperatur und Zeit (nach Henser 1955). Im Temperaturbereich zwischen $23^{\circ}$ und $20^{\circ} \mathrm{C}$ erreicht die Impulsrate - und damit das Generatorpotential - ein Maximum. Mit abfallenden Temperaturen ändert sich der Adaptationstyp, und die Zeitkonstante der steady-state-Einstellung nimmt zu. Q $\mathrm{Q}_{3}$ : Temperaturquotient der Impulsrate für Temperatursprünge von $3^{0} \mathrm{C}$

Beispiel bestimmte temperaturempfindliche Organe (Lorenzinische Ampullen von Selachiern) (HENSEL 1951), welche bei stufenweiser Temperaturveränderung in einem bestimmten Punkt der Temperaturskala eine optimale Reaktion zeigen (Abb. 11). Es stellt sich die Frage, ob auch solche Systeme durch Fließgleichgewichtsmodelle abgebildet werden können. Dies ist tatsächlich der Fall, wenn man zur Abbildung eines abzweigenden biochemischen Reaktionszuges einen Querleitwert $G_{q}$ parallel zur Kapazität $\mathrm{C}_{2}$ schaltet und diesen "temperaturempfindlichen" Geschwindigkeitskoeffizienten zugleich mit einem weiteren Koeffizienten $\left(G_{1}\right)$ stufenweise in Analogie zur Temperaturwirkung auf das System erniedrigt (WILLIAM \& ZERBST 1964). Abbildung 12 zeigt eine solche Ersatzschaltung und gibt im Diagramm die notwendigen Leitwertveränderungen für den Modellversuch wieder. Interessant ist hierbei, daß das biologische Objekt und das Modellsystem nicht nur im Hinblick auf ein spezielles Amplituden- 
maximum übereinstimmen, sondern auch im Hinblick auf die Veränderung der Zeitkonstanten bei der Kurzzeitadaptation und den Typ der Adaptation.

Fließgleichgewichtsmodelle komplexer Systeme: Bisher wurde gezeigt, daß einfache Fließgleichgewichtssysteme prinzipiell die gleichen ReizReaktionsbeziehungen aufweisen, wie sie im biologischen Experiment unter verschie-

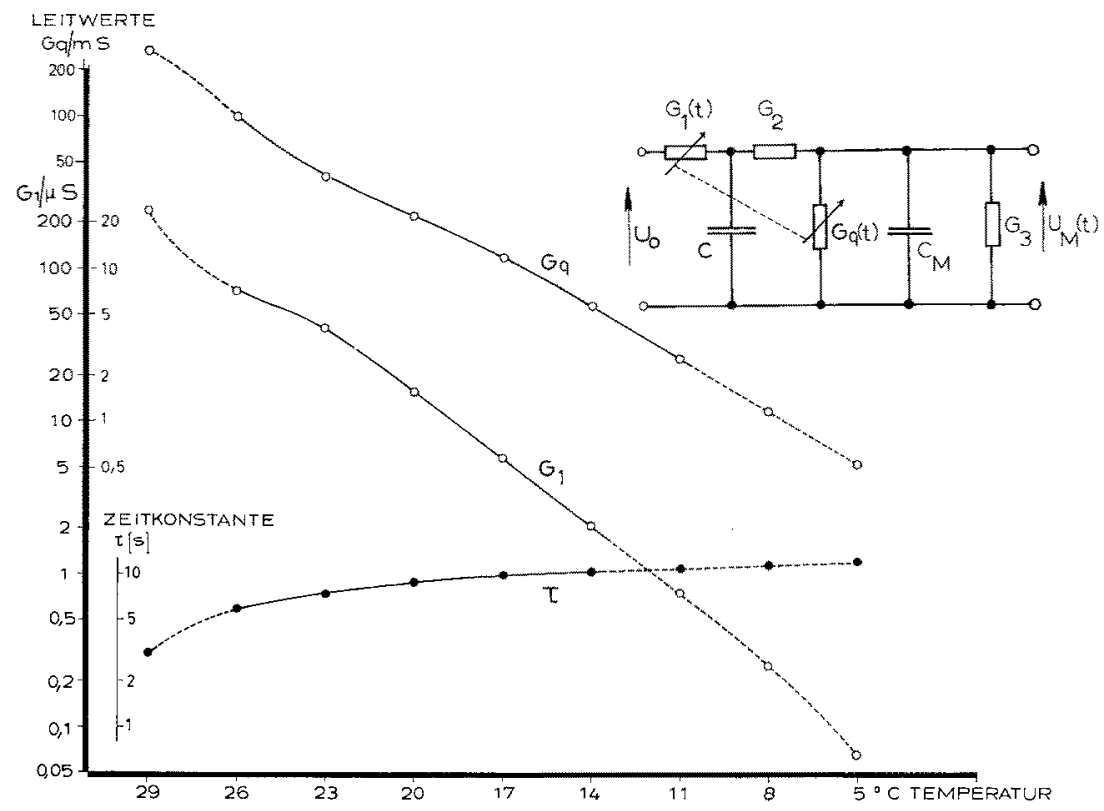

Abb. 12: Ersatzschaltung für das Fließgleichgewichtsmodell eines Kaltrezeptors (oben rechts) und Darstellung der temperaturproportionalen Leitwertveränderungen von $G_{1}$ und $G_{\gamma}$. In Analogie zur Temperaturwirkung auf zwei verschieden empfindliche Reaktionen im offenen Stoff wechselsystem werden im Modellyersuch die "Geschwindigkeitskoeffizienten " $G_{1}$ und $G_{q}$ nach der im Diagramm dargestellten Weise verändert. Führt man diese Leitwertverstellungen stufenweise (für je $3^{\circ} \mathrm{C}$ ) durch, dann ist von $\mathrm{CM}_{M}$ ein Rezeptorpotential mit dem in Abbildung 11 dargestellten Zeitgang abzuleiten. Es besteht Ubereinstimmung mit der Reaktion des biologischen Objekts (Maximalwert bei bestimmter „Temperatur“, Wechsel des Typs der Kurzzeitadaptation, Zunahme der Zeitkonstanten der steady-state-Einstellung mit fallender „Temperatur"). (Nach WrLltaM \& ZERBST 1964)

densten Reizbedingungen zu erhalten sind. Dabei wurde von der Voraussetzung ausgegangen, daß der "Reiz“ direkt an der entscheidenden Koeffizientengröße ( $\left.G_{2}\right)$ angreift. Wir müssen aber annehmen, daß am biologischen Objekt die Verhältnisse wesentlich komplexer sind. Zur Behandlung der Frage, ob auch komplexe Systeme durch Fließgleichgewichtsmodelle abgebildet werden können, schaltet man zum Beispiel drei Vierpolsysteme zur Darstellung der parametrischen Beeinflussung des Sinneszellstoffwechsels und des Rezeptormembranstoffwechsels zusammen. Man erhält dementsprechende Resultate. Zugleich wird bei dieser Anordnung deutlich, daß die Latenzzeitbildung von den Zeitkonstanten der miteinander gekoppelten Fließgleichgewichtsübergänge abhängt. 


\section{ZUR THEORIE DER ERSATZSCHALTUNGEN}

Die hier an einem Fließgleichgewichtssystem demonstrierten Modellversuche bejahen demnach die eingangs gestellte Frage, ob in den Reiz-Reaktionsbezichungen eine formale Ubereinstimmung $z$ wischen einfachen Fließgleichgewichtssystemen und biologischen PD-Rezeptoren besteht (vgl. Zerbst, Dittberner \& William 1965a, b). Offen bleibt allerdings die Frage nach den spezifischen biochemischen oder bioelektrischen

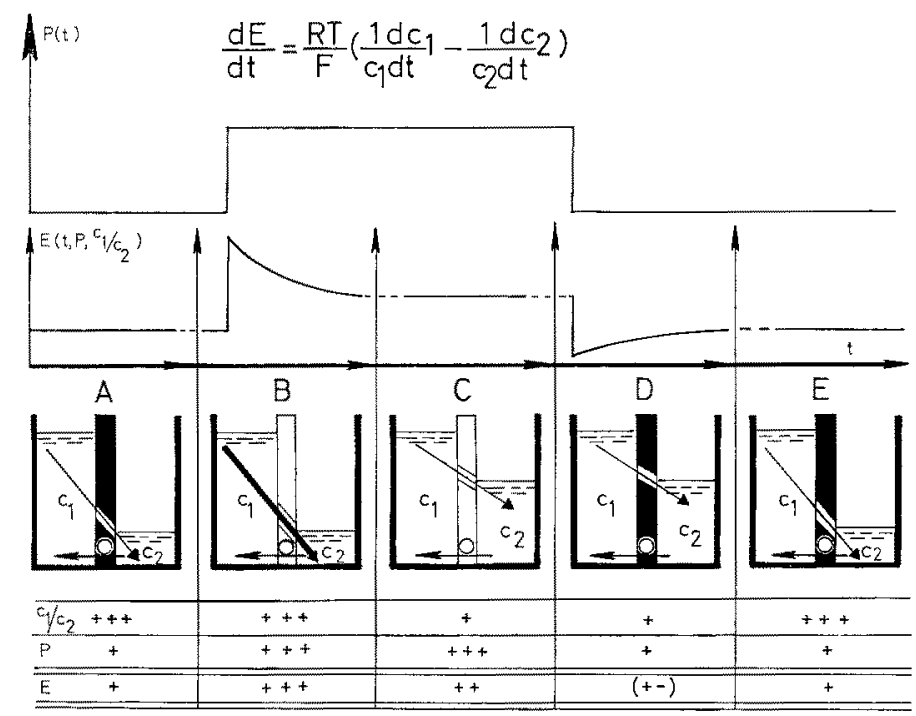

Abb. 13: Schematische Darstellung der Abhängigkeit der Ionenpotentialgröße von der Fließgleichgewichtskonzentration der einzelnen Ionenarten. Oben: Differentialgleichung der NERNSTschen Gleichung. Oberes Diagramm: Reizproportionaler Zeitgang der Membranpermeabilitätsveränderung ( $\mathrm{P}$ : Permeabilität). Mittleres Diagramm: Potentialverlauf $(\mathrm{E}$ als Funktion von $\left.t, P, C_{1} / C_{2}\right)$. $C_{1}$ und $C_{2}$ : Ionenaktivitäten in den Kompartimenten beiderseits der Membran

Vorgängen, die als Fließgleichgewichtssysteme innerhalb des Zellstoffwechsels die Bildung des Rezeptorpotentials bedingen könnten. An anderer Stelle (ZERBST, DitTrBeRNER \& WILlIAM 1964a, b, 1965a, b) wurde untersucht, ob solche Fließgleichgewichtsübergänge bereits allein aus der Kinetik des aktiven und passiven Ionentransports an der Rezeptormembran herzuleiten sind. Dabei wurde davon ausgegangen, daß - im Gegensatz zu den Verhältnissen an den Schnürringen des Nerven - zwischen Potentialgröße und Ionenpermeabilität keine Rückkopplungsbeziehungen bestehen, wie sie die Hodgrin-HuxLEysche Theorie fordert. Es wurde vielmehr angenommen, daß ein Reiz - direkt oder indirekt - eine permanente und reizstärkenproportionale Permeabilitätsveränderung für $\mathrm{Na}^{+}$- und andere Ionen auslöst.

Unter dieser Annahme gelten die in der Abbildung 13 schematisch dargestellten Beziehungen zwischen Ionenpotential, Ionenaktivitätsdifferenz beiderseits der Membran und aktiven beziehungsweise passiven Transportkoeffizienten. Mathematisch läßt sich dies auch durch die Differenzierung der NerNstschen Gleichung ausdrücken. Das 
Schema der Abbildung 13 deutet an, daß im Zeitabschnitt A (vor der Reizung) eine relativ geringe Membranpermeabilität für die potentialbestimmende Ionenart besteht. Es treten entlang dem Konzentrationsgefälle zwischen $C_{1}$ und $C_{2}$ permanent Ionen durch die Membran. Gleichzeitig wird aber eine entsprechende Ionenmenge aktiv gegen das Konzentrationsgefälle transportiert, wodurch die Konzentrationsdifferenz konstant bleibt. Die Aktivitätsdifferenz ist relativ hoch $\left(\mathrm{C}_{1} / \mathrm{C}_{2}+++\right)$, die Permeabilität niedrig $(\mathrm{P}+)$, das resultierende Potential gering $(\mathrm{E}+)$. Im Zeitabschnitt $\mathrm{B}$ wird durch einen Reiz die passive Permeabilität erhöht. Die Erhöhung des spezifischen Ionenleitwertes führt in diesem Falle gemäß der Goldmanschen Beziehung zu einem Anstieg des Potentials. Dieses Potential erreicht aber nur vorübergehend einen Spitzenwert und fällt dann näherungsweise exponentiell wieder bis zu einem steady-state-Wert ab. Der Potentialabfall ist dadurch bedingt, daß - bei gleichbleibender aktiver Transportrate wegen der erhöhten Permeabilität mehr Ionen passiv entlang dem Konzentrationsgefälle wandern als aktiv gegen das Gefälle transportiert werden. So kommt es schließlich (Zeitabschnitt C) zu einer Verminderung der Ionenaktivitätsdifferenz beiderseits der Membran. Im Zeitpunkt $D$ wird der Reiz abgesetzt, und die Permeabilität kehrt auf den geringeren Ausgangswert zurück, gleichzeitig ist aber die Aktivitätsdifferenz noch immer relativ klein. Das resultierende Ionenprodukt wird daher zuerst sehr gering, steigt dann aber allmählich mit zunehmender Aktivitätsdifferenz der Ionenart wieder an, um schließlich seinen alten Wert vor der Reizung (Zeitabschnitt E) zu erreichen. Das ist auf die im Zeitabschnitt D relativ größere aktive Transportrate gegen die Konzentrationsdifferenz zurückzuführen. Die Ionenpumpe hat gegen ein geringeres

Tabelle 1

Analogiebezichungen zwischen elektrischen und chemischen Größen anhand der jeweiligen Transportgleichungen (vgl. Abb. 14 oben)

\begin{tabular}{|c|c|}
\hline \multicolumn{2}{|c|}{ Gleichungen } \\
\hline der elektrischen Ersatz-Schaltung: & der Adaptationstheorie von RANKE: \\
\hline $\mathrm{i}_{1}=\mathrm{g}_{1}\left(\mathrm{U}_{0}-\mathrm{u}_{\mathrm{C}}\right)$ & $\begin{array}{l}\text { Bildungsgeschwindigkeit } \mathrm{v}_{1} \\
\mathrm{v}_{1}=\mathrm{Lk}_{1}(\mathrm{a}-\mathrm{ax})\end{array}$ \\
\hline $\mathrm{i}_{2}=\mathrm{G}_{2} \mathrm{u}_{\mathrm{C}}$ & $\begin{array}{l}\text { Rüdkbildungsgeschwindigkeit v2 } \\
\mathrm{v} 2_{2}=\mathrm{k}_{2} \mathrm{ax}\end{array}$ \\
\hline
\end{tabular}

Gefälle zu arbeiten, deshalb überwiegt zu diesem Zeitpunkt die Rate des aktiven Transports gegenüber der Rate des passiven Ioneneinstromes. Die ursprüngliche Konzentrationsdifferenz und das ursprïngliche Potential sind wieder erreicht, sobald ein Fließgleichgewicht, das heißt ein gleich großer passiver und aktiver Ionenfluß eingestellt ist. Eine ausführliche mathematische Behandlung dieser Arbeitshypothese erfolgt an anderer Stelle (DitTBerner, ZeRbST \& William 1967).

Selbstverständlich kommen für die Potentialbildung nach Reizung nicht nur die Fließgleichgewichtsübergänge im System des aktiven und passiven Ionentransports an der Rezeptormembran in Frage. Man kann entsprechende Ubergänge auch für andere 
Abschnitte des Sinneszellenstoffwechsels postulieren. So haben RANke \& KEIDEL (1960, 1962) - ausgehend von der Fließgleichgewichtskinetik des Sinneszellstoffwechsels - eine mathematische Adaptationstheorie abgeleitet, bei welcher ebenfalls reizanaloge Koeffzientenveränderungen $z u$ den Stoffwechselübergängen im offenen System führen. Als

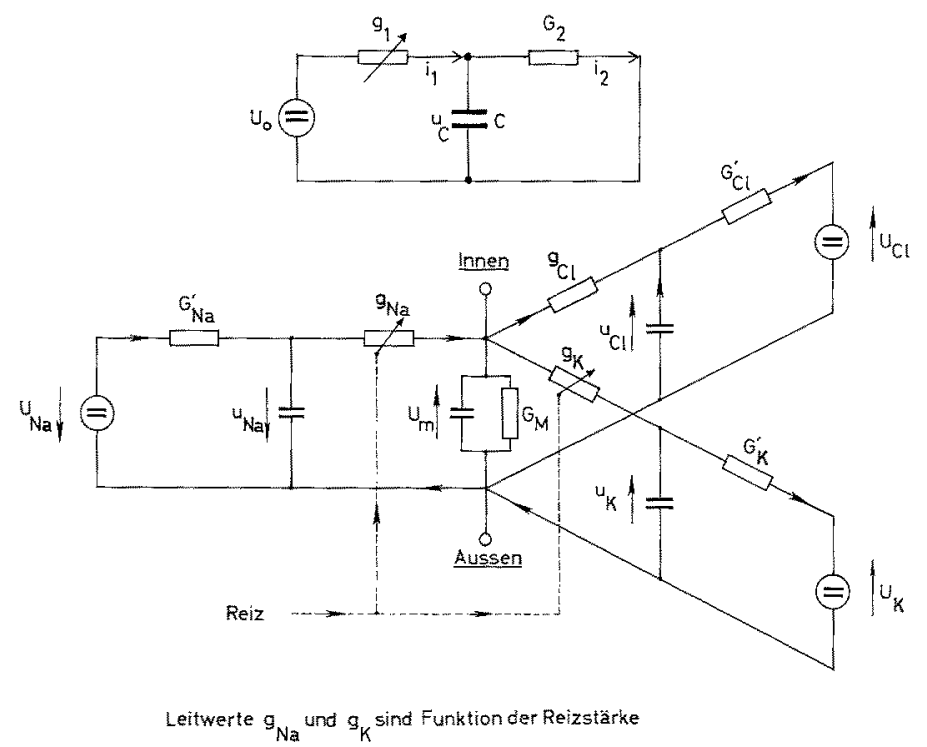

Abb. 14: Gegenüberstellung der Fließgleichgewichtssysteme der RANkEschen Adaptationstheorie und der Membranhypothese von Zerbst, DitTBERner \& William (1964) (Abbildung der Systeme durch Ersatzschaltungen). Oben: Ersatzschaltung zur RaNKEschen Theorie. Unten: Ersatzschaltung für ein Rezeptor-Membranelement. Aktiver und passiver Transport von $\mathrm{Na}{ }^{+}$, $\mathrm{K}^{+}$und Restionen ist durch je einen Vierpolzweig abgebildet. Die jeweils wirksamen Ionenpotentiale liegen zusammen auf der Membrankapazität $\mathrm{C}_{\mathrm{M}}$. In Analogie zur parametrischen Reizwirkung werden die passiven Permeabilitäten der Ionenzweige verändert (vgl. ZERBST, DitTBERNER \& WiLliam 1964)

Reaktion auf einen Reiz wurde in dieser Theorie die Umsatzgeschwindigkeit eines speziellen Sinneszell-Stoffwechselproduktes betrachtet. In Abbildung 14 (oben) haben wir für die RANKEsche Adaptationstheorie eine Ersatzschaltung auf Grund der Analogiebeziehungen zwischen den elektrischen Transportgleichungen dieser und den allgemeinen chemischen Transportgleichungen der Rankeschen Theorie (Tabelle 1) demonstriert. Eine Gegenüberstellung des Systems von RANKE und des Ersatzschaltungsprinzips für den aktiven und passiven Ionentransport an der Membran (Abb. 14 unten) zeigt die unterschiedliche Komplexität der beiden Modellyorstellungen. Die RANKEsche Hypothese erlaubt zwar ebenfalls eine Deutung des Kennlinienverlaufes und eine Erklärung der Unterschiedsschwellenempfindlichkeit in den verschiedenen Reizintensitätsbereichen. Dagegen kann man mit ihr eine - im biologischen Bereich häufig zu beobachtende - Kennlinienverschiebung nicht deuten. Mit Hilfe des komplexeren Membranmodells (Zerbst, DitTBerner \& William 1965a) wird das aber möglich.

Durch Umrechnungen nach den Prinzipien der Kompartiment-Theorie (DrtrberNER, ZeRbST \& WILLIAM 1967) kann die komplexe Ersatzschaltung der Abbildung 14 
auf das einfache System der Abbildung 2 reduziert werden. Die für dieses System geltenden Differentialgleichungen sind:

$$
\begin{aligned}
& \frac{d u_{A}}{d t}=\frac{1}{R_{1} C_{A}}\left(U_{S}-u_{A}\right)-\frac{u_{A}}{R_{2} C_{A}}+\frac{u_{B}}{R_{2} C_{A}} \\
& \frac{d u_{B}}{d t}=\frac{u_{A}}{R_{2} C_{B}}-\frac{u_{B}}{R_{2} C_{B}}-\frac{1}{R_{3} C_{B}}\left(u_{B}-u_{Z}\right)
\end{aligned}
$$

Zur mathematischen Beschreibung der Vorgänge bei der Impulsbildung durch Rezeptorzellen wurde erstmals von SAND (1938) die sogenannte Zwei-FaktorenTheorie herangezogen, später wurde diese von Hensel \& ZotTERmann (1951) und Hensel (1953) in ähnlicher Form entwickelt. Für die Impulsbildung nach Reizsprung gibt die Zwei-Faktoren-Theorie die folgende Lösungsfunktion an:

$$
\mathrm{F}(t)=\left(a-F_{2}\right) \mathrm{e}^{-t / k_{E}}+F_{2}-\left(a-F_{1}\right) \mathrm{e}^{-t / k_{H}}
$$

Dabei kennzeichnet $F_{1}$ die Ausgangsrate der Impulse vor dem Reiz, $F_{2}$ die steadystate-Rate nach Reizsprung; $a$ ist eine Konstante, $k_{E}$ ist die Zeitkonstante des Erregungsvorganges und $k_{H}$ die Zeitkonstante des Hemmungsvorganges. $E$ und $H$ werden als zwei verschiedene Reaktionen (chemische Reaktionen des erregenden und hemmenden Stoffwechselzweiges) betrachtet. Ihre Geschwindigkeit hängt von der Reizstärke ab. Der Ansatz nach Gleichung (3) wurde von KeIDEL (1956) kritisiert. Die e-Funktionen decken die gemessenen Werte des biologischen Experimentes nur dann, wenn als dritte Größe der steady-state-Frequenzwert addiert wird, andernfalls würden die e-Funktionen zum Nullwert zurückführen.

Die Lösungsfunktion aus den Gleichungen (1) und (2) für den Potentialverlauf bei Sprungreiz am elektrischen Fließgleichgewichtsmodell hat abgekürzt die Form:

$$
u_{B}(t)=\left(U^{\prime \prime}{ }_{B}-U_{B 2}\right) \exp \left(-\frac{t-t_{1}}{\tau_{z}}\right)+U_{B 2}-\left(U^{\prime \prime}{ }_{B}-U_{B 1}\right) \exp \left(-\frac{t-t_{1}}{\tau_{a}}\right)
$$

Vergleicht man die Gleichungen (3) und (4), so wird die formale Identität der Funktionen deutlich, das heißt die Gleichung der Zwei-Faktoren-Theorie ist eine Lösungsfunktion eines einfachen Fließgleichgewichtssystems. Die Sprungfunktion für das elektrische Fließgleichgewichtsmodell enthält die steady-state-Größe $U_{B 2}$ als definierte Größe und muß also nicht wie in der Form (3) empirisch ermittelt werden. Auf eine ausführliche mathematische Behandlung kann hier nicht weiter eingegangen werden; sie findet sich bei DitTrerner, Zerbst \& William (1967). Es sei aber erwähnt, daß durch die mathematische Analyse experimenteller, das heißt neurophysiologisch registrierter Generatorpotentiale im Hinblick auf die einzelnen Systemgrößen (Koeffizienten, Potentiale, kapazitive Größen) quantitative Angaben möglich werden.

Zur Anwendung bei kybernetischen Untersuchungen ist eine Realisierung des Fließgleichgewichtsmodelles für einen Rezeptor mit Hilfe elektrischer Schaltelemente zu empfehlen. Die Abbildung 15 gibt als Beispiel ein entsprechendes Schaltbild. Zur Programmierung auf einem Analogrechner kann der in Abbildung 16 dargestellte Koppelplan verwendet werden. Durch Zusammenschaltung mehrerer Modelleinheiten lassen sich Versuche zur Analyse und Simulation der "lateralen Hemmung" und der „on-off“-Neurone anstellen. 


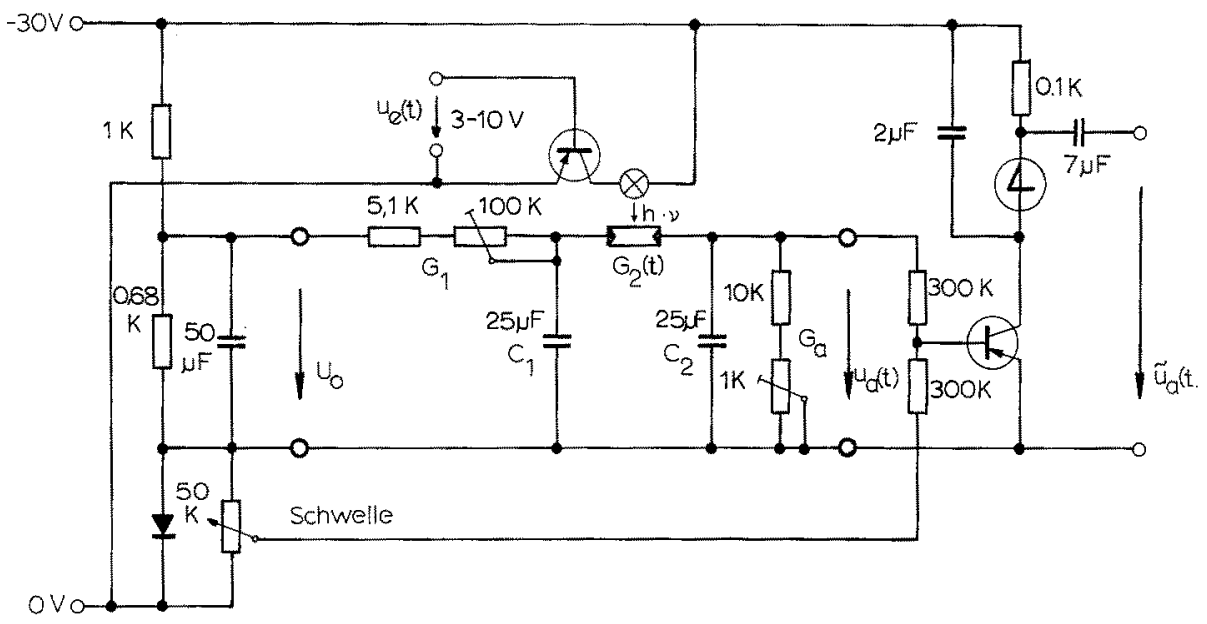

Abb. 15: Realisierung eines einfachen Rezeptormodelles mit Hilfe elektronischer Schaltelemente. $\mathrm{U}_{0}$ : Eingangsspannung des Vierpols mit den Leitwerten $\mathrm{G}_{1}, \mathrm{G}_{2}$ und $\mathrm{G}_{2}$ und den Kapazitätex $\mathrm{C}_{1}$ und $\mathrm{C}_{2} ; \mathrm{u}_{\mathrm{a}}(\mathrm{t})$ : Abgriff des "Rezeptorpotentials"; $\mathrm{u}_{\mathrm{e}}(\mathrm{t})$ : Steuerspannung der Glühlampe (Reizquelle); $\tilde{\mathfrak{u}}_{2}(t)$ : Abgriff zur Registrierung der fortgeleiteten Potentiale. Durch Veränderung der Steuerspannung $\mathrm{u}_{\mathrm{e}}(\mathrm{t})$ wird die Lichtintensität $(\mathrm{h} \cdot v)$ der Glühlampe als Reizgröße variiert. Diese "Reizgröße" löst durch Veränderung des Leitwertes am Photowiderstand $\left(\mathrm{G}_{2}\right)$ die steady-state-UUbergänge des Systems aus

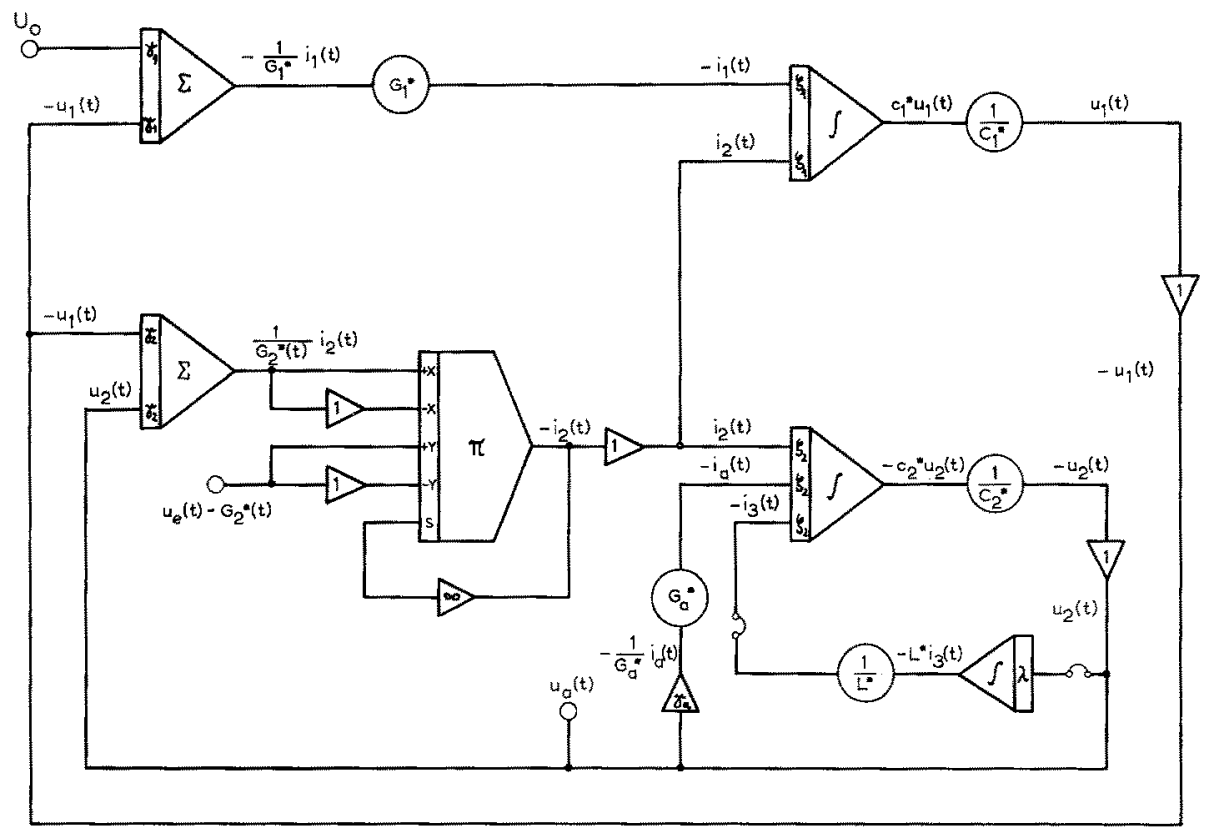

Abb. 16: Realisierung eines einfachen Rezeptormodelles auf dem elektronischen Analogrechner. Koppelplan für die Ersatzschaltung beziehungsweise das Gleichungssystem der Abbildung 2 (vgl. DitTBERner, Zerbst \& WILLIAM 1967) 
Schließlich wird es auch möglich, unter Bezugnahme auf die definitiven Größen des Rezeptormodelles die Informationskapazität $(J)$ eines Rezeptorkanales zu errechnen.

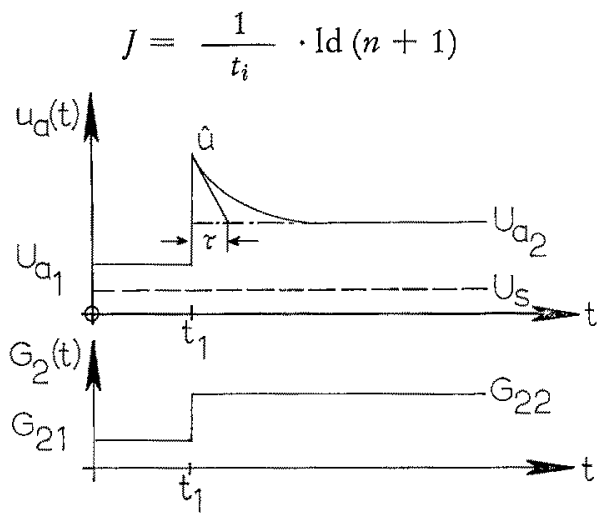

Abb. 17: Schematischer Ansatz zur Berechnung der Informationskapazität eines RezeptorModellkanals (vgl. Dittrerner, Zerbst \& William 1967)

Gemäß dem schematischen Ansatz der Abbildung 17 wird die Informationskapazität nach dem "Reiz", das heißt ab $t_{1}$ betrachtet. Ohne Adaptation des Rezeptors wird:

$$
J=\frac{1}{t_{i}} \mathrm{ld}\left(t_{i} \frac{U_{a 2 \mathrm{max}}-U_{s}}{\Delta U}+1\right)
$$

mit Adaptation:

$$
J=\frac{1}{t_{i}} \operatorname{ld}\left(t_{i} \frac{U_{a \max }-U_{s}}{\Delta U}+t_{i} \frac{\hat{U}_{a t}-U_{a 2}}{\Delta U} \exp (-t / \tau)+1\right)
$$

wobei:

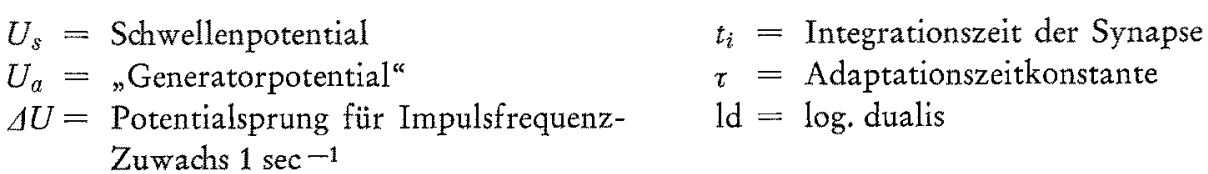

Eine ausführliche Diskussion findet sich bei Dittrerner, Zerbst \& William (1967).

\section{ZUSAMMENFASSUNG}

1. Die bisher zur Verfügung stehenden wichtigsten Informationen über Reiz-Reaktions-Beziehungen biologischer PD-Rezeptoren werden mit den allgemeinen thermodynamischen Grundeigenschaften biologischer Fließgleichgewichtssysteme koordiniert.

2. Aus dieser Koordination ergibt sich eine systemtheoretische Arbeitshypothese über die Ursache der Rezeptorpotentialbildung. Der Potentialverlauf unter verschiedensten Reizbedingungen kann auf Fließgleichgewichtsübergänge im offenen Stoff- 
wechselsystem der Rezeptorzelle zurückgeführt werden. Zusatzannahmen regeltechnischer Natur sind hierbei nicht notwendig.

3. Zu klären bleibt die Frage nach der speziellen Natur des jeweils wirksamen Fließgleichgewichtssystems. Theoretisch läßt sich die Potentialbildung bereits aus den Fließgleichgewichtsübergängen des aktiven und passiven Ionentransports deuten. Sicher sind aber daran auch Ubergänge des allgemeinen Zell- oder des speziellen Transmitter-Stoff wechsels beteiligt.

4. Die Arbeitshypothese wird im Modellversuch überprüf. Es wird gezeigt, daß unter allen Reizbedingungen und Reizvariationen eine gute Ubereinstimmung zwischen biologischen Rezeptorreaktionen und Reaktionen einfacher Fließgleichgewichtssysteme zu finden ist.

5. Es werden Ausblicke auf die Verwendungsmöglichkeiten des Modellprinzips gegeben. Das Modell ist heuristisch wertvoll, weil formale quantitative Analysen und der Ansatz weiterer gezielter Experimente (z. B. Feststellung des im Sinneszellstoffwechsel maßgeblichen Fließgleichgewichtssystems) möglich werden. Die Arbeitshypothese ermöglicht somit den Ansatz quantitativer Betrachtungen zur Informationsaufnahme und -verarbeitung durch biologische PD-Rezeptoren.

\section{ZITIERTE LITERATUR}

Adrian, E. D., 1928. The basis of sensation. Christopher, London, $122 \mathrm{pp.}$

Bemmann, F. W. \& Meissner, H. D., 1961. Zum Mechanismus der Temperaturadaptation. Pflügers Arch. ges. Physiol. 274, 76-77.

- 1962. Zur nichtzentralen Temperaturanpassung des Gewebsstoffwechsels. Pflügers Arch. ges. Physiol. 276, 82-88.

Bertalanffy, L. von, 1951. Der Organismus als offenes System. In: Bertalanffy: Theoretische Biologie. Bd 2: Stoff wechsel, Wachstum. 2. Auff. Frandke, Bern, 49.

- 1953. Biophysik des Fließgleichgewichts. Vieweg, Braunschweig, 56 pp.

- 1962. General system theory - a critical review. Gen. Syst. 7, 1-20.

- 1964. Basic concepts in quantitative biology of metabolism. Helgoländer wiss. Meeresunters. 9, 5-37.

Burkhardt, D., 1962. Spectral sensitivity and other response characteristics of single visual cells in the arthropod eye. In: Biological receptor mechanisms. Ed. by J. W. L. Beament. Cambridge Univ, pr., London (Symp. Soc. exp. Biol. 16, 86-109).

Burton, A. C., 1939. The properties of steady-state compared to those of equilibrium as shown in characteristic biological behavior. J. cell. comp. Physiol. 14,327-348.

Denbigh, G. K., Hicks, M. \& PAGE, F. M., 1948. The kinetics of open reaction systems. Trans. Faraday Soc. 44, 439-494.

DitT'Berner, K.-H., Zerbst, E. \& William, E., 1967. Über die Nachrichtenaufnahme durch biologische Receptoren. 2. Mitt.: Das vereinfachte Receptormodell, seine mathematischen, regeltechnischen und informationstheoretischen Eigenschaften. Kybernetik (in Vorbereitung).

Drischel, H., 1952. Die Meßfunktion biologischer Rezeptoren als regeltheoretisches Problem. Naturwissenscbaften 39, 496-504.

GRüsszR, O. J., 1952. Rezeptorabhängige Potentiale der Katzenretina und ihre Reaktion auf Flimmerlicht. Pflügers Arch. ges. Physiol. 271, 511-525.

Hensel, H., 1953. The time factor in thermoreceptor excitation. Acta plyysiol. scand. 29, $109-116$.

- \& Zottermann, J., 1951. Quantitative Beziehungen zwischen der Entladung einzelner Kältefasern und der Temperatur. Acta physiol. scand. 23, 291-297. 
Hodgrin, A. L. \& Huxley, A. F., 1952. A quantitative description of membrane current and its application to conduction and excitation in nerve. J. Physiol., Lond. 117, 500-545.

KeIDeL, W. D., 1955. Aktionspotentiale des N. dorsocutaneus bei Vibration der Froschrückenhaut. Pflïgers Arch. ges. Physiol. 260, 337-347.

- 1956. Vibrationsrezeption. Der Erschütterungssinn des Menschen. Erlanger Forsch. (B) 2.

- 1961. Rankes Adaptationstheorie. Z. Biol. 112, 411-425.

KIKUCHI, R. \& TAZAWA, M., 1960. Effect of intensity, duration and interval of stimulus on retinal slow potential. In: Electrical activity of single cells. Igaku Shoin, Tokio.

Merxner, J. \& Reik, H. G., 1959. Thermodynamik der irreversiblen Prozesse. In: Handbuch der Physik. Hrsg. von S. Flügge. Springer, Berlin, Bd 3, T. 2, 1-413.

Ranke, O. F., 1960. Physiologie des Zentralnervensystems vom Standpunkt der Regelungslehre. Urban \& Schwarzenberg, München, $133 \mathrm{pp}$.

SAND, A., 1938. The function of the ampullae Lorenzini with some observations on the effect of temperature on sensory systems. Proc. $R$. Soc. (B) 125, 524-532.

THuRM, U., 1964. Adaptation eines Mechanorezeptors. Pfïgers Arch. ges. Physiol. $281,86$.

WiLliam, E. \& Zerbst, E., 1964. Ein Vierpol als Analogmodell biologischer Rezeptoren. Elektron. Rdsch. 18, 264-266.

ZERBST, E., 1963a. Eine Methode zur Analyse und quantitativen Auswertung biologischer steady-state Ubergänge. Experientia 19, 166-168.

- 1963b. Die Analyse biologischer Aupassungsvorgänge mit der Methode der Thermodynamik irreversibler Prozesse. Pflügers Arch. ges. Physiol. 278, 91.

- 1963c. Untersuchungen zur Veränderung energetischer Fließgleichgewichte bei physiologischen Anpassungsvermögen. Mitt. 1.2. Pflïgers Arch. ges. Physiol. 277, 434-457.

- 1964. Ein Analogrechenverfahren zur Analyse biologischer Anpassungsvorgänge mit der Methode der Thermodynamik irreversibler Prozesse. Helgoländer wiss. Meeresunters. 9, 380-391.

- 1965a. Membranmodelle zur Darstellung biologischer PD-Rezeptorfunktion. In: Int. Symp. f. elektrochem. Aspekte und Methoden in der Molekularbiologie. Jena, Mai 1965, 15.

- 1965b. Fließgleichgewichte in Organismen und Modellen. Acta medicotechn. 13, 148-152.

- Dittberner, K.-H. \& William, E., 1964. Untersuchungen zur prinzipiellen Abbildung der Sinneszellfunktion am elektrischen Rezeptormodell. Pflügers Arch. ges. Pbysiol. 279, R. 6.

- - 1965a. Membranmodelle zur Darstellung biologischer Rezeptorpotentiale. Abb. dt. Akad. Wiss., Berl. (Kl. Medizin) 1966, 265-279.

- - 1965b: Uber die Nachrichtenaufnahme durch biologische Receptoren. 1. Mitt.: Theoretische Untersuchungen zur Ursache der Erregungsbildung. Kybernetik 2, 160-168.

- \& Willtam, E., 1964. Computer, Simulatoren und Analogmodelle. Zur technischen Abbildung biologischer Vorgänge. Acta medicotechn. 9, 370-372.

- - \& DitTBerner, K.-H., 1964. Untersuchungen zum Kausalmechanismus biologischer Rezeptorfunktionen mit Hilfe elektrischer Ersatzschaltungen. In: TagBer. Gemeins. Tag. d. Dt. Ges. f. Biophysik, Osterr. Ges. f. Biophysik, Schweiz. Ges. f. Strahlenbiol., Wien, $487-490$.

\section{Diskussion im Anschluß an den Vortrag Zerbst, Dittrenner \& William}

LOCKER: Es würde mich interessieren, in welcher Beziehung die von Ihnen gegenüber HodGKIN-KATZ erweiterte Ersatzschaltung (beziehungsweise die zugrunde liegenden Gleidhungen) zur Generalisierung der HoDGKIN-Huxhey-Gleichungen stehen, die D. AgIN (J. theor. Biol. $5,161,1963 ;$ Nature, Lond. 201, 625, 1964) gegeben hat. Eine einfache für die Anderung des Membranpotentials im Muskel ausreichende Ersatzschaltung hat neuerdings A. Frumento (Science, N. Y. 147, 1442, 1965) gegeben.

ZERBST: Von der HoDGKIN-HuXLEY- beziehungsweise HodGKIN-KATz-Theorie unterscheidet sich unsere Arbeitshyporhese grundsätzlich in den folgenden Punkten: (1) Die HoDGKrn-Katzsche Ersatzschaltung gilt für die Abbildung fortgele it e ter Aktionspotentiale des Alles- 
oder Nichts-Typs. Unsere Ersatzschaltung bildet ausschließlich die Rezeptor- beziehungsweise Generator-potentiale des graduierten Typs ab. (2) Zur Abbildung der Alles-oder-Nichts-Entladungen (Kippschwingungssystem) müssen bei HoDGKIN-KaTz Rückkopplungsbeziehungen zwischen dem jeweiligen Membranpotential und der Leitwertgröße für $g_{\mathrm{N}_{2}}$ und $g_{\mathrm{K}}$ angenommen werden. Bei D. AgIN finden sich darüber hinaus noch Rückkopplungsbeziehungen zum Restionenleitwert. Zur Abbildung der graduierten Potentiale (Fließgleichgewichtsystem) sind die Leitwerte $g_{\mathrm{Na}}$ und $\mathrm{gk}_{\mathrm{K}}$ nur und ausschließlich eine Funktion der Reizstärke. Das HodgkinHuXley-Katz-System enthält also regulative Elemente 2. Ordnung (nach v. Bertalanfay), unsere Arbeitshypothese dagegen nur solche 1. Ordnung. (3) Nach Hodgkin-Huxuey wird angenommen, daß die Ionendiffusionspotentiale ( $U_{\mathrm{Na}}, \mathrm{U}_{\mathrm{K}}$ und $\mathrm{U}_{\mathrm{Cl}}$ ) reizunabhängig stets $\mathrm{k}$ on $s \tan t$ bleiben. Vorausgesetzt wird dabei pauschal eine entsprechende Wirkung aktiver Ionentransportmechanismen, die im einzelnen jedoch nicht in die Gleichungssysteme miteingeht. In unserer Arbeitshypothese nimmt die $\mathrm{A} n \mathrm{de}$ r u n g der Diffusionspotentiale in Abhängigkeit von der jeweiligen aktiven und passiven Ionentransportrate die zentrale Stellung ein; die Potentiale uNa, uK und $u_{\mathrm{Ol}}$ sind Funktion der Ionenaktivitätsdifferenzen außen/innen. Die Ionenaktivitätsdifferenzen sind Funktion der aktiven und passiven Ionenflüsse. Die passiven Ionenflüsse sind Funktion der jeweiligen Permeabilitüten, letztere Funktion der Reizintensität. Das Membranpotential ist (analog der Goldman-Beziehungen) Funktion der Permeabilitäten und der sich mit der Reizdauer verändernden Ionenpotentiale. Die unserer Arbeitshypothese zugrunde liegenden Gleichungen unterscheiden sich also von den generalisierenden Gleichungen bei AGIN (a) durch Fehlen der Rückkopplungsbeziehungen zwischen Membranpotential und Ionenleitwerten und (b) durch Annahme einer zeitlichen Anderung der Diffusionspotentiale in Abhängigkeit von der Bilanz des aktiven und passiven Ionentransports durch die Membran. In der Ersatzschaltung von Frumento werden die durch aktiven Ionentransport bedingten aktiven $\mathrm{Na}$ - und $\mathrm{K}-\mathrm{Ströme} \mathrm{p}$ a $\mathrm{r}$ a $11 \mathrm{e}$ l zu den passiven Ein- beziehungsweise Auswärtsströmen an der Membran betrachtet; sie erlaubt nicht - wie das bei uns möglich ist - eine bilanzmäßige Betrachtung der die jeweiligen Diffusionspotentiale bestimmenden Transportvorgänge. Bei uns sind aktive und passive Transportraten (quasi „im Kreis") hintereinandergeschaltet. Die FrumenTo-Ersatzschaltung erlaubt ferner nicht die Simulation aller bisher bekannten Reiz-Reaktionsbeziehungen an der Rezeptormembran, was bei unserer Schaltung möglich ist. 